Article

\title{
Empathy, Burnout, and Attitudes towards Mental Illness among Spanish Mental Health Nurses
}

\author{
Daniel Román-Sánchez ${ }^{1}$, Juan Carlos Paramio-Cuevas ${ }^{1}$, Olga Paloma-Castro ${ }^{2}$, José Luis Palazón-Fernández ${ }^{1}$, \\ Isabel Lepiani-Díaz ${ }^{1}$ (D) José Manuel de la Fuente Rodríguez ${ }^{1}$ and María Reyes López-Millán ${ }^{2, * \mathbb{C}}$ \\ 1 Nursing Faculty "Salus Infirmorum", University of Cadiz, 11001 Cadiz, Spain; \\ daniel.roman@ca.uca.es (D.R.-S.); paramio@msn.com (J.C.P.-C.); joseluispalazonf@gmail.com (J.L.P.-F.); \\ isabel.lepiani@gmail.com (I.L.-D.); jfuenter@hotmail.com (J.M.d.l.F.R.) \\ 2 Nursing Department, University of Cadiz, 11001 Cadiz, Spain; olga.paloma@uca.es \\ * Correspondence: reyes.lopez@uca.es; Tel.: +34-727-751-212
}

Citation: Román-Sánchez, D.; Paramio-Cuevas, J.C.; Paloma-Castro,

O.; Palazón-Fernández, J.L.;

Lepiani-Díaz, I.; de la Fuente Rodríguez, J.M.; López-Millán, M.R. Empathy, Burnout, and Attitudes towards Mental Illness among Spanish Mental Health Nurses. Int. J. Environ. Res. Public Health 2022, 19, 692. https://doi.org/10.3390/ ijerph19020692

Academic Editor: Paul B. Tchounwou

Received: 29 November 2021

Accepted: 6 January 2022

Published: 8 January 2022

Publisher's Note: MDPI stays neutral with regard to jurisdictional claims in published maps and institutional affiliations.

Copyright: (C) 2022 by the authors. Licensee MDPI, Basel, Switzerland. This article is an open access article distributed under the terms and conditions of the Creative Commons Attribution (CC BY) license (https:// creativecommons.org/licenses/by/ $4.0 /)$.

\begin{abstract}
Mental health nurses, together with psychiatrists, are the healthcare professionals who display the highest levels of empathy and the best attitudes towards patients with mental disorders. However, burnout is a common problem among these professionals. The aim of our study is to describe the association between empathy, burnout, and attitudes towards patients with mental disorders among mental health nurses in Spain. A descriptive cross-sectional design was used involving a sample of 750 specialist nurses working in mental health facilities in Spain. An intentional, non-probability, non-discriminative, exponential snowball sampling method was used. The Jefferson Scale of Empathy, the Maslach Burnout Inventory, and the Community Attitudes towards Mental Illness Inventory were used to measure the study variables. A positive correlation was observed between empathy and all the study variables, with the exception of the personal accomplishment dimension of burnout and the social restrictiveness and authoritarianism dimensions of attitudes towards mental illness, where a negative relation was observed. Our findings suggest that empathy is associated with an increase in positive attitudes towards patients with mental disorders, decreasing associated stigma, but did not act as a protective factor against burnout in the study sample.
\end{abstract}

Keywords: acute mental health; empathy; nursing role; stigma

\section{Introduction}

The stigma of mental illness is a reality in our society, especially among healthcare professionals [1,2]. Empathy among mental health nurses is a key element helping to reduce stigma towards patients with mental disorders [3]. In addition, mental health nurses often experience the well-known burnout syndrome, which reduces the quality of their professional work [4]. An analysis of the associations between these variables may provide a better understanding of how they interact among mental health nurses working directly with patients with mental disorders in Spain.

Empathy is a multidimensional construct [5] responsible for perceiving the experiences, concerns, and perspectives of another individual without losing reference to one's own self [6]. Empathy may be modified by receiving training and through individual and work experience [7].

Multiple benefits related to empathy have been described in the healthcare setting, such as improved healthcare, improved professional-patient relations, better adherence to treatment, better clinical outcomes, and increased patient satisfaction, and increased satisfaction in healthcare professionals [8-10]. Moreover, empathy is the interpersonal skill most highly valued by both healthcare professionals and patients [11]. However, the international literature reports that there are significant differences between men and women [12-14]. 
It has also been shown that the number of years worked, stressful experiences, lack of time, lack of contact with other professionals, and pressure on the health system make it difficult for healthcare professionals to interact empathetically, thereby empathy decreases and burnout increases [15]. This syndrome has been reported to be experienced by between $30 \%$ and $40 \%$ of nurses worldwide [16] and is described as a set of symptoms including depersonalization, emotional exhaustion, and lack of personal accomplishment [17], leading to communication problems and a poor understanding of patients' needs [16]. In these cases, there is evidence that high levels of empathy act as a protective factor against burnout [18].

Nursing is the health profession with the highest levels of empathy in its relation with patients according to Petrucci et al. [19]. The construct of empathy is considered a key communication skill for nursing [20] and therefore, a number of studies on empathy have focused on nursing professionals [21].

Within the field of nursing, the mental health nursing specialty bases most of its actions on communication therapies [22], in which empathy helps to reduce negative attitudes towards patients with mental disorders. Tippin and Maranzan [3] argue that improving attitudes towards mentally ill patients decreases stigma, which is considered a negative emotional, behavioral, or cognitive response to individuals with a mental disorder [23-25]. A recent review of the literature reaffirms that empathy continues to be an essential component of the nurse-patient therapeutic relation in current mental health units [26]. For this reason, mental health nurses are the health professionals who, together with psychiatrists, display the highest levels of empathy and the best attitudes towards users with mental disorders $[27,28]$.

A number of studies suggest that empathy is one of the factors that, together with the experience of caring for mental health patients, protects mental health nurses against burnout and increases the bond with mentally ill patients by positively modifying their attitudes towards them [29].

Empathy, burnout, and the relation between them among mental health nurses have been studied previously. Often independently or relating only to empathy and burnout $[12,30]$. However, our study is the first to address the relation between empathy, burnout, and attitudes towards patients with mental disorders among mental health nurses in the Spanish national health system. Moreover, few studies have been conducted on the levels of empathy among mental health nurses [12,31]. We can add that the number of studies that investigate these variables is small and most of the studies have not been carried out in Spain [3,12,28,31,32].

We believe that it would be desirable for mental health nurses to have high levels of empathy and attitudes towards patients with mental disorders, as well as low levels of burnout.

The aim of this study is thus to describe the levels of empathy, burnout, and attitudes towards patients with mental disorders among mental health nurses and their sociodemographic variables and to describe the relation between these variables. We hypothesized that high empathy (independent variable) is related to lower burnout (lower emotional exhaustion, lower depersonalization and higher personal accomplishment) and better attitudes towards patients with mental disorders (lower authoritarianism and social restrictiveness, higher benevolence and community mental health ideology).

\section{Materials and Methods}

\subsection{Study Design and Participants}

This is a descriptive cross-sectional study conducted at mental health facilities in the Spanish national health system. This research adheres to the STROBE guidelines [33] for the reporting of observational studies. All nurses who met the eligibility criteria were included in the study: (i) being a mental health nurse specialist, and; (ii) performing their healthcare work in mental health facilities in the Spanish national health system at the time of the study. An intentional, non-probability, non-discriminative, exponential snowball 
sampling method was used [34] aiming to recruit eligible subjects from different parts of Spain. This type of sampling helps us to access hard-to-reach populations, expand the sample size and facilitate data validation. Sampling starts from the selection of the initial collaborators called "seeds", these will not enter the subsequent analysis. The seeds select a certain number of new participants that will be useful for the analysis and so on [35]. This study involved an initial population of 4000 nurses working in mental health facilities in the Spanish national health system, as estimated by the Spanish National Association of Mental Health Nurses (Asociación Nacional de Enfermería de Salud Mental) [36]. To recruit the study subjects, we had collaborators in the different mental health units of the different Spanish autonomous communities (seeds). The measurement instruments necessary for carrying out the study were disseminated through them, making them available to the maximum number of mental health nurses possible. For the recovery of the data, personal contact was made with the collaborators of the units where the procedure needed to be carried out. All mental health facilities were contacted by email and 750 nurses agreed to participate in the study by completing an anonymous online questionnaire on empathy, burnout, and attitudes towards mentally ill patients between March and November 2019. Participants gave informed consent and their data were coded to ensure confidentiality.

\subsection{Instruments and Variables}

- $\quad$ Empathy. Empathy was measured using the Spanish version of the Jefferson Scale of Empathy (JSE) [37] containing 20 items related to empathic response in patient care settings. Ten of them are worded positively and the other 10 are worded negatively to avoid unreflective answers. Each item is scored on a 7-point Likert scale ranging from 1 (strongly disagree) to 7 (strongly agree). Scores are reversed for negative items, which means that individuals responding 'strongly disagree' score 7 points. The score for each subscale is the sum of the points obtained on all the items; however, negatively worded items are scored inversely. The total scores range from 20 to 140 points. High scores indicate high levels of empathy. In the adaptation to Spanish, it has been shown to have high internal consistency and a reliability close to 90\% (Cronbach's Alpha: 0.82). The JSE is currently the most widely used instrument to measure this variable [19].

- Burnout. Burnout among healthcare professionals was measured using the Spanish version of the Maslach Burnout Inventory (MBI) [38]. It consists of 22 items in the form of statements about professionals' feelings and attitudes towards their work and patients. Respondents rate the frequency with which they experience these feelings on a 7-point Likert scale ranging from 0 (never) to 6 (every day). The MBI includes 3 dimensions: emotional exhaustion (MBI-EE), who values the experience of being emotionally exhausted by labor demands, depersonalization (MBI-DP) examines the degree to which each person recognizes attitudes of emotional coldness and detachment, and personal accomplishment (MBI-PA) assesses feelings of self-efficacy and personal fulfillment at work. The score for each subscale is the sum of the points obtained on all the items; however, negatively worded items are scored inversely. High scores on MBI-EE and MBI-DP and low scores on MBI-PA indicate high levels of burnout [38]. In the adaptation to Spanish, this scale has a high internal consistency and a reliability close to $90 \%$ (Cronbach's Alpha values: 0.90 for the emotional exhaustion; 0.79 for depersonalization, and 0.71 for personal accomplishment). Currently, the original MBI [39] is considered the most valued and most widely used instrument for measuring burnout in both national and international studies.

- Attitudes towards mentally ill patients were measured using the Spanish version of the Community Attitudes towards Mental Illness (CAMI) inventory [40]. The scale has been used in a variety of populations: nurses, psychiatrists, family members, as well as in the general population. It consists of 40 items rated on a 5-point Likert scale ranging from 1 (strongly agree) to 5 (strongly disagree) and is made up of 4 factors: authoritarianism (CAMI-A) designed to assess community attitudes toward 
the mentally ill, benevolence (CAMI-B) examines welcoming attitudes to patients, social restrictiveness (CAMI-SR) assesses the belief of danger to society of people with mental disorder, and community mental health ideology (CAMI-CMH) determines the beliefs related to the insertion into society of people with mental disorders. Each factor is divided into 10 statements addressing views on how to treat and care for individuals with a mental disorder. Five of the 10 items on each subscale are worded positively, while the other 5 are worded negatively. The score for each subscale is the sum of the points obtained on all the items; however, negatively worded items are scored inversely, i.e., when respondents give a score of 5 to an item expressed negatively, the score is considered to be 1 . High scores on CAMI-B and CAMI-CMH and low scores on CAMI-A and CAMI-SR indicate high levels of attitudes towards mental health patients. In the adaptation to Spanish, this instrument has an internal consistency of 90\% (Cronbach's Alpha: 0.861).

- Other variables. The following sociodemographic data were collected: age, gender, years worked as a nurse, and years worked as a mental health nurse.

\subsection{Statistical Analysis}

Qualitative variables (gender) were described using absolute and relative frequencies. Quantitative variables (age, years working as a nurse, years working as a mental health nurse, JSE, MBI, and CAMI) were expressed as medians and interquartile ranges (IQR), as they showed significant deviations from the normal distribution according to the Kolmogorov-Smirnov test. The reliability of the JSE, MBI, and CAMI scales was assessed using Cronbach's alpha. The correlation between the JSE, MBI, and CAMI scores and between these and sociodemographic variables was assessed using Spearman's rank correlation coefficient (rho).

Comparisons of quantitative variables between two groups were performed using the Mann-Whitney U test and comparisons of quantitative variables between three or more groups were performed using the Kruskal-Wallis test. All tests were two-tailed, setting the statistical significance threshold at 0.05 . The type 1 family-wise error rate was controlled at 0.05 by the Holm-Bonferroni correction [41]. Missing values were deleted in a pairwise fashion. There was only $0.03 \%$ of missing data and they were deleted in a pairwise fashion. All analyses were performed using IBM's SPSS ${ }^{\circledR}$ (version 25.0) software (IBM Corp., Armonk, NY, USA).

\subsection{Ethical Considerations}

This research was approved by the Research Ethics Committee. The study strictly adheres to the general principles of bioethics, current legislation on health research, and Spanish Organic Law 3/2018, of the 5th of December, on Personal Data Protection and the Guarantee of Digital Rights. The privacy of the study participants was preserved at all times through the use of an anonymous database.

\section{Results}

The characteristics of the 750 study participants are shown in Tables 1-5. The majority of participants were female $(62.5 \%)$ and had more than 20 years of professional experience as nurses (59.7\%). Many were between 40 and 49 years of age (35.7\%) and had also been working in mental health facilities for more than 20 years (47.6\%) (Table 1$)$. 
Table 1. Descriptive demographic and work-related data of the participants.

\begin{tabular}{|c|c|}
\hline Variable & $\mathbf{N}=750$ \\
\hline \multicolumn{2}{|l|}{ Gender } \\
\hline Male & $281(37.5 \%)$ \\
\hline Female & $469(62.5 \%)$ \\
\hline \multicolumn{2}{|l|}{ Age } \\
\hline Male & $47.0(41.0-55.5)$ \\
\hline Female & $44.0(36.0-54.0)$ \\
\hline \multicolumn{2}{|l|}{ Age groups } \\
\hline$<30$ & $25(3.3 \%)$ \\
\hline $30-39$ & $174(23.2 \%)$ \\
\hline $40-49$ & $268(35.7 \%)$ \\
\hline $50-59$ & $194(25.9 \%)$ \\
\hline$>60$ & $89(11.9 \%)$ \\
\hline \multicolumn{2}{|c|}{ Years as a nurse } \\
\hline Male & $25.0(20.0-34.0)$ \\
\hline Female & $22.0(14.0-31.0)$ \\
\hline \multicolumn{2}{|c|}{ Groups of years as a nurse } \\
\hline$<5$ & $22(2.9 \%)$ \\
\hline $5-10$ & $78(10.4 \%)$ \\
\hline $11-15$ & $75(10.0 \%)$ \\
\hline $16-20$ & $127(16.9 \%)$ \\
\hline$>20$ & $448(59.7 \%)$ \\
\hline \multicolumn{2}{|c|}{ Years in mental health } \\
\hline Male & $22.0(16.0-30.0)$ \\
\hline Female & $19.0(10.0-28.0)$ \\
\hline \multicolumn{2}{|c|}{ Groups of years in mental health } \\
\hline$<5$ & $67(8.9 \%)$ \\
\hline $5-10$ & $95(12.7 \%)$ \\
\hline $11-15$ & $86(11.5 \%)$ \\
\hline $16-20$ & $145(19.3 \%)$ \\
\hline$>20$ & $357(47.6 \%)$ \\
\hline
\end{tabular}

Quantitative variables are expressed as medians (IQRs). Qualitative variables are expressed as frequencies (\%).

The reliability of the scales used was good, meeting the criteria of being between the range of 0.7 and 0.9 [42], except for the MBI total score and the MBI-DP. In addition, Cronbach's alpha analysis showed that the CAMI questionnaire had a low level of reliability (Cronbach's alpha: 0.460). Detailed analysis of the scale items showed that most of the items were to be maintained, resulting in a decrease in the alpha value if removed, with the exception of items 9 and 29, whose removal increased the alpha value and were negatively correlated with the total. It was therefore decided to exclude them from the analysis (Cronbach's alpha values: 0.779 for the JSE; 0.534 for MBI; 0.880 for MBI-EE; 0.524 for MBI-DP; 0.854 for MBI-PA; 0.817 for CAMI-A; 0.725 for CAMI-B; 0.850 for CAMI-SR, and 0.841 the CAMI-CMH).

\subsection{Empathy}

Table 2 shows the results obtained for empathy. Significant differences $(p<0.05)$ were observed based on gender, age groups, years as an unspecialized nurse, and years as a mental health nurse. The level of empathy increased with an increase in these variables. A positive correlation $(p<0.05)$ can be observed between empathy and all the study variables, with the exception of the personal accomplishment dimension of burnout and the social restrictiveness and authoritarianism dimensions of attitudes towards mentally ill patients, where a negative correlation is observed $(p<0.05)$ (Table 3$)$. These results mean that high empathy is associated with higher burnout since the higher the levels of empathy, the higher the levels of emotional exhaustion and depersonalization and the lower the levels of personal accomplishment which, as Maslach indicated, are the main prerequisites for causing burnout [38]. In addition, high empathy is associated with 
better attitudes towards mentally ill patients, since the higher the levels of empathy, the higher the levels of benevolence and community mental health ideology and the lower the levels of authoritarianism and social restrictiveness, as explained by the measurement instrument [40].

Table 2. Association between empathy and sociodemographic variables.

\begin{tabular}{|c|c|c|}
\hline Variable & $\begin{array}{l}\text { Total Empathy } \\
\text { Median } \\
\text { (IQR) }\end{array}$ & $p$-Value \\
\hline Gender & $130.0(128.0-132.0)$ & 0.031 \\
\hline Male & $130.0(129.0-132.0)$ & \\
\hline Female & $130.0(128.0-132.0)$ & \\
\hline Age groups & & 0.000 \\
\hline$<30$ & $124.0(121.0-129.5)$ & \\
\hline $30-39$ & $129.0(126.0-130.0)$ & \\
\hline $40-49$ & $130.0(129.0-131.0)$ & \\
\hline $50-59$ & $131.0(128.0-132.0)$ & \\
\hline$>60$ & $132.0(130.5-133.0)$ & \\
\hline Years as a nurse & & 0.000 \\
\hline$<5$ & $126.0(121.0-129.25)$ & \\
\hline $5-10$ & $127.0(124.0-130.0)$ & \\
\hline $11-15$ & $129.0(127.0-130.0)$ & \\
\hline $16-20$ & $130.0(128.0-131.0)$ & \\
\hline$>20$ & $131.0(129.0-132.0)$ & \\
\hline Years in mental health & & 0.000 \\
\hline$<5$ & $126.0(121.0-129.0)$ & \\
\hline $5-10$ & $129.0(126.0-130.0)$ & \\
\hline $11-15$ & $130.0(128.0-131.0)$ & \\
\hline $16-20$ & $130.0(128.0-131.0)$ & \\
\hline$>20$ & $131.0(129.0-132.0)$ & \\
\hline
\end{tabular}

\subsection{Burnout}

Table 4 shows the results obtained for burnout and its dimensions. Significant differences $(p<0.05)$ were observed in both total MBI and MBI dimensions between age groups, years as an unspecialized nurse, and years as a mental health nurse. No significant genderbased differences $(p>0.05)$ in the total MBI were observed, but they were observed in the MBI dimensions: men obtained higher values in the emotional exhaustion dimension and in the depersonalization dimension, while women obtained higher values in the personal accomplishment dimension. A positive correlation $(p<0.05)$ can be observed between the burnout total, emotional exhaustion and depersonalization dimensions of burnout and all the study variables, with the exception of the personal accomplishment dimension of burnout and the social restrictiveness and authoritarianism dimensions of attitudes towards mentally ill patients, with which a negative correlation is observed $(p<0.05)$. In addition, a negative correlation $(p<0.05)$ can be observed between the personal accomplishment dimension of burnout and all the study variables, with the exception of the dimensions of social restrictiveness and authoritarianism of attitudes towards patients with mental disorders, with which a positive correlation is observed $(p<0.05)$. All observed correlations were weak $(>0.20)$ or moderate $(>0.50)$, with the exception of the correlation between the total MBI and the dimensions of emotional exhaustion and depersonalization. The correlation between the emotional exhaustion dimension and personal accomplishment was also strong (>0.70) (Table 3). 
Table 3. Spearman's rank correlation matrix between study variables.

\begin{tabular}{|c|c|c|c|c|c|c|c|c|c|c|c|c|c|}
\hline VARIABLES & $\begin{array}{l}\text { Empathy } \\
\text { (JSE) }\end{array}$ & $\begin{array}{c}\text { Total } \\
\text { Burnout } \\
\text { (MBI) }\end{array}$ & $\begin{array}{c}\text { Emotional } \\
\text { Exhaustion } \\
\text { (MBI-EE) }\end{array}$ & $\begin{array}{l}\text { Depersonalization } \\
\text { (MBI-DP) }\end{array}$ & $\begin{array}{c}\text { Personal } \\
\text { Accomplishment } \\
\text { (MBI-PA) }\end{array}$ & $\begin{array}{l}\text { Total Community } \\
\text { Attitudes towards } \\
\text { Mental Illness } \\
\text { (CAMI) }\end{array}$ & $\begin{array}{l}\text { Authoritaria-nism } \\
\text { (CAMI-A) }\end{array}$ & $\begin{array}{l}\text { Benevolence } \\
\text { (CAMI-B) }\end{array}$ & $\begin{array}{c}\text { Social } \\
\text { Restrictiveness } \\
\text { (CAMI-SR) }\end{array}$ & $\begin{array}{c}\text { Community } \\
\text { Mental Health } \\
\text { Ideology } \\
\text { (CAMI-CMH) }\end{array}$ & Age & $\begin{array}{l}\text { Years as } \\
\text { a Nurse }\end{array}$ & $\begin{array}{l}\text { Years in } \\
\text { Mental } \\
\text { Health }\end{array}$ \\
\hline JSE & 1 & & & & & & & & & & & & \\
\hline Total MBI & 0.247 ** & 1 & & & & & & & & & & & \\
\hline MBI-EE & $0.204 * *$ & $0.817^{* *}$ & 1 & & & & & & & & & & \\
\hline MBI-DP & 0.179 ** & 0.717 ** & 0.656 ** & 1 & & & & & & & & & \\
\hline MBI-PA & -0.072 * & $-0.299 * *$ & -0.732 ** & -0536 ** & 1 & & & & & & & & \\
\hline Total CAMI & 0.072 * & $0.279 *$ & $0.251^{* *}$ & 0.171 ** & -0.087 * & 1 & & & & & & & \\
\hline CAMI-A & $-0.419^{* *}$ & $-0.170^{* *}$ & $-0.226 * *$ & $-0.250 * *$ & $0.252 * *$ & $0.214 * *$ & 1 & & & & & & \\
\hline CAMI-B & 0.292 ** & 0.200 ** & $0.140^{* *}$ & 0.152 ** & -0.024 & 0.398 ** & -0.323 ** & 1 & & & & & \\
\hline CAMI-SR & $-0.396^{* *}$ & $-0.170^{* *}$ & $-0.228 * *$ & $-0.207 * *$ & 0.239 ** & 0.121 ** & 0.693 ** & $-0.397 * *$ & 1 & & & & \\
\hline Age & $0.360 * *$ & 0.405 ** & 0.581 ** & $0.468^{* *}$ & $-0.568^{* *}$ & -0.006 & -0.549 ** & 0.180 ** & $-0.522 * *$ & $0.525^{* *}$ & 1 & & \\
\hline Years as a nurse & $0.367 * *$ & 0.378 ** & $0.555^{* *}$ & 0.432 ** & $-0.543 * *$ & -0.009 & -0.560 ** & 0.187 ** & $-0.536 * *$ & 0.533 ** & $0.973 * *$ & 1 & \\
\hline $\begin{array}{l}\text { Years in mental } \\
\text { health }\end{array}$ & $0.392 * *$ & 0.409 ** & 0.566 ** & 0.451 ** & $-0.527^{* *}$ & -0.008 & $-0.569^{* *}$ & $0.181^{* *}$ & $-0.541^{* *}$ & $0.538^{* *}$ & $0.942 * *$ & $0.962^{* *}$ & 1 \\
\hline
\end{tabular}

${ }^{*}$ indicates a significant correlation, $p<0.05 .{ }^{* *}$ indicates a significant correlation, $p<0.01$. 
Table 4. Association between burnout and sociodemographic variables.

\begin{tabular}{|c|c|c|c|c|}
\hline Variable & $\begin{array}{l}\text { Total Burnout } \\
\text { (MBI) }\end{array}$ & $\begin{array}{l}\text { Emotional } \\
\text { Exhaustion } \\
\text { (MBI-EE) }\end{array}$ & $\begin{array}{l}\text { Depersonalization } \\
\text { (MBI-DP) }\end{array}$ & $\begin{array}{c}\text { Personal } \\
\text { Accomplishment } \\
\text { (MBI-PA) }\end{array}$ \\
\hline Gender & $55.0(51.0-59.0)$ & $11.0(6.0-15.0)$ & $3.0(2.0-4.0)$ & $41.0(38.0-44.0)$ \\
\hline Male & $55.0(52.0-60.0)$ & $12.0(7.0-16.0)$ & $3.0(2.0-4.5)$ & $41.0(38.0-43.0)$ \\
\hline Female & $55.0(51.0-58.0)$ & $10.0(5.0-15.0)$ & $2.0(2.0-4.0)$ & $42.0(38.0-45.0)$ \\
\hline$p$-value & 0.106 & 0.033 & 0.003 & 0.015 \\
\hline \multicolumn{5}{|l|}{ Age groups } \\
\hline$<30$ & $52.0(46.0-66.0)$ & $8.0(2.0-22.5)$ & $2.0(0.0-5.5)$ & $39.0(35.5-45.0)$ \\
\hline $30-39$ & $52.0(49.0-55.0)$ & $4.0(2.0-9.0)$ & $2.0(1.0-3.0)$ & $46.0(43.0-47.5)$ \\
\hline $40-49$ & $54.0(50.0-57.0)$ & $9.0(6.0-13.0)$ & $2.0(2.0-3.0)$ & $42.0(41.0-44.0)$ \\
\hline $50-59$ & $57.0(53.0-61.0)$ & $14.0(11.0-16.0)$ & $4.0(2.0-5.0)$ & $40.0(37.0-41.0)$ \\
\hline$>60$ & $59.0(56.0-64.0)$ & $18.0(15.0-21.0)$ & $5.0(3.5-7.0)$ & $36.0(34.0-39.0)$ \\
\hline$p$-value & 0.000 & 0.000 & 0.000 & 0.000 \\
\hline \multicolumn{5}{|l|}{ Years as a nurse } \\
\hline$<5$ & $50.0(46.0-59.25)$ & $7.0(0.0-16.0)$ & $2.0(0.0-4.25)$ & $43.5(36.75-47.0)$ \\
\hline $5-10$ & $52.0(48.0-56.25)$ & $4.0(2.0-11.25)$ & $2.0(1.0-3.0)$ & $46.0(41.0-47.0)$ \\
\hline $11-15$ & $52.0(49.0-56.0)$ & $5.0(2.0-8.0)$ & $2.0(1.0-3.0)$ & $46.0(42.0-48.0)$ \\
\hline $16-20$ & $54.0(49.0-57.25)$ & $8.0(4.0-11.0)$ & $2.0(1.0-3.0)$ & $43.5(41.0-46.0)$ \\
\hline$>20$ & $56.0(53.0-60.0)$ & $13.0(10.0-16.0)$ & $3.0(2.0-5.0)$ & $40.0(37.0-42.0)$ \\
\hline$p$-value & 0.000 & 0.000 & 0.000 & 0.000 \\
\hline \multicolumn{5}{|c|}{ Years in mental health } \\
\hline$<5$ & $51.0(47.0-56.0)$ & $4.0(0.0-16.0)$ & $2.0(0.0-3.0)$ & $45.0(37.0-47.0)$ \\
\hline $5-10$ & $52.0(50.0-56.0)$ & $4.0(2.0-8.0)$ & $2.0(1.0-3.0)$ & $47.0(42.0-48.0)$ \\
\hline $11-15$ & $53.0(48.0-57.0)$ & $7.0(4.0-10.25)$ & $2.0(1.0-3.0)$ & $44.0(41.0-46.0)$ \\
\hline $16-20$ & $54.0(50.0-57.0)$ & $9.0(6.0-12.0)$ & $2.0(2.0-3.0)$ & $42.0(41.0-44.0)$ \\
\hline$>20$ & $57.0(54.0-61.0)$ & $14.0(11.0-17.0)$ & $3.0(3.0-5.0)$ & $40.0(37.0-42.0)$ \\
\hline$p$-value & 0.000 & 0.000 & 0.000 & 0.000 \\
\hline
\end{tabular}

\subsection{Attitudes towards Mentally Ill Patients}

Table 5 shows the results obtained for attitudes towards mentally ill patients and its dimensions. In the total CAMI there were no significant differences $(p>0.05)$ based on gender, years as an unspecialized nurse, and years as a mental health nurse, but there were significant differences between age groups $(p<0.05)$. Regarding the CAMI dimensions, significant differences $(p<0.05)$ were observed in relation to age groups, years as an unspecialized nurse, and years as a mental health nurse. Gender-based differences were observed only in the dimensions of authoritarianism and social restrictiveness, where women obtained higher values. A negative correlation $(p<0.05)$ can be observed between the authoritarianism dimension and all study variables, with the exceptions of the social restrictiveness dimension and the total score of attitudes towards patients with mental disorders, as well as the personal accomplishment dimension of burnout, where a positive correlation $(p<0.05)$ is observed. A positive correlation $(p<0.05)$ can be observed between the benevolence and community mental health ideology dimensions and all the study variables, with the exceptions of the social restrictiveness and authoritarianism dimensions of attitudes towards patients with mental disorders, as well as the personal accomplishment dimension of burnout, where a negative correlation is observed $(p<0.05)$. A negative correlation $(p<0.05)$ was identified between the social restrictiveness dimension and all study variables, with the exceptions of the authoritarianism dimension and the total score of attitudes towards mentally ill patients, as well as the personal accomplishment dimension of burnout, where a positive correlation $(p<0.05)$ is observed. All identified correlations were moderate $(>0.50)$ or weak $(>0.20)$, with the exception of the correlation between the dimensions of social restrictiveness and community mental health ideology $(>0.70)$ (Table 3). 
Table 5. Association between attitudes towards mental health patients and sociodemographic variables.

\begin{tabular}{|c|c|c|c|c|c|}
\hline Variable & $\begin{array}{l}\text { Total Community } \\
\text { Attitudes towards } \\
\text { Mental Illness } \\
\text { (CAMI) }\end{array}$ & $\begin{array}{l}\text { Authoritarianism } \\
\text { (CAMI-A) }\end{array}$ & $\begin{array}{l}\text { Benevolence } \\
\text { (CAMI-B) }\end{array}$ & $\begin{array}{c}\text { Social } \\
\text { Restrictiveness } \\
\text { (CAMI-SR) }\end{array}$ & $\begin{array}{l}\text { Community } \\
\text { Mental Health } \\
\text { Ideology } \\
\text { (CAMI-CMH) }\end{array}$ \\
\hline Gender & $114.0(113.0-115.0)$ & $9.0(8.0-9.0)$ & $46.0(45.2-46.0)$ & $12.0(10.0-13.0)$ & $47.0(45.0-49.0)$ \\
\hline Male & $114.0(113.0-115.0)$ & $9.0(8.0-9.0)$ & $46.0(46.0-46.0)$ & $12.0(10.0-13.0)$ & $47.0(45.0-50.0)$ \\
\hline Female & $114.0(113.0-115.0)$ & $9.0(8.0-10.0)$ & $46.0(45.0-46.0)$ & $13.0(11.0-14.0)$ & $47.0(45.0-49.0)$ \\
\hline$p$-value & 0.136 & 0.000 & 0.127 & 0.003 & 0.056 \\
\hline \multicolumn{6}{|l|}{ Age groups } \\
\hline$<30$ & $114.0(113.0-116.5)$ & $12.0(10.0-15.5)$ & $45.0(44.0-46.0)$ & $16.0(13.0-18.0)$ & $44.0(38.0-47.0)$ \\
\hline $30-39$ & $114.0(112.7-116.0)$ & $9.0(9.0-11.0)$ & $46.0(45.0-46.0)$ & $13.0(12.0-14.25)$ & $45.0(44.0-47.0)$ \\
\hline $40-49$ & $114.0(112.0-115.0)$ & $9.0(8.0-9.0)$ & $46.0(46.0-46.0)$ & $13.0(11.0-13.0)$ & $46.0(45.0-48.0)$ \\
\hline $50-59$ & $114.0(113.0-115.0$ & $8.0(8.0-9.0)$ & $46.0(46.0-46.0)$ & $11.0(10.0-13.0)$ & $49.0(46.0-50.0)$ \\
\hline$>60$ & $114.0(114.0-114.0)$ & $8.0(8.0-8.0)$ & $46.0(46.0-46.0)$ & $10.0(10.0-10.0)$ & $50.0(50.0-50.0)$ \\
\hline$p$-value & 0.018 & 0.000 & 0.000 & 0.000 & 0.000 \\
\hline \multicolumn{6}{|c|}{ Years as a nurse } \\
\hline$<5$ & $114.0(113.0-15.25)$ & $10.0(9.0-13.5)$ & $45.5(44.0-46.0)$ & $15.0(12.0-17.25)$ & $44.0(39.75-46.25)$ \\
\hline $5-10$ & 114.5 (112.0-117.25 & $10.0(9.0-12.0)$ & $46.0(45.0-46.0)$ & $14.0(12.0-15.0)$ & $45.0(42.75-47.25)$ \\
\hline $11-15$ & $114.0(113.0-115.0)$ & $9.0(9.0-10.0)$ & $46.0(45.0-46.0)$ & $13.0(12.0-14.0)$ & $46.0(44.0-47.0)$ \\
\hline $16-20$ & $114.0(112.0-115.0)$ & $9.0(9.0-9.0)$ & $46.0(45.0-46.0)$ & $13.0(12.0-14.0)$ & $46.0(44.0-48.0)$ \\
\hline$>20$ & 114.0 (113.0-114.0) & $8.0(8.0-9.0)$ & $46.0(46.0-46.0)$ & $11.0(10.0-13.0)$ & $48.0(46.0-50.0)$ \\
\hline$p$-value & 0.208 & 0.000 & 0.000 & 0.000 & 0.000 \\
\hline \multicolumn{6}{|c|}{ Years in mental health } \\
\hline$<5$ & $114.0(112.0-117.0)$ & $10.0(9.0-12.0)$ & $46.0(44.0-46.0)$ & $14.0(12.0-16.0)$ & $45.0(41.0-47.0)$ \\
\hline $5-10$ & $114.0(112.0-115.0)$ & $9.0(9.0-10.0)$ & $46.0(45.0-46.0)$ & $13.0(13.0-14.0)$ & $45.0(43.0-47.0)$ \\
\hline $11-15$ & $114.0(112.0-115.0)$ & $9.0(9.0-9.0)$ & $46.0(45.0-46.0)$ & $13.0(12.0-14.0)$ & $45.5(44.0-48.0)$ \\
\hline $16-20$ & $114.0(112.0-115.0)$ & $9.0(9.0-9.0)$ & $46.0(45.0-46.0)$ & $13.0(11.0-13.0)$ & $46.0(45.0-48.0)$ \\
\hline$>20$ & $114.0(113.0-114.0)$ & $8.0(8.0-9.0)$ & $46.0(46.0-46.0)$ & $11.0(10.0-13.0)$ & $49.0(46.0-50.0)$ \\
\hline$p$-value & 0.220 & 0.000 & 0.000 & 0.000 & 0.000 \\
\hline
\end{tabular}

Median (IQR), Total CAMI = community attitudes towards mental illness; CAMI-A = authoritarianism; CAMI-B = benevolence; CAMI-SR = social restrictiveness; CAMI-CMH = community mental health ideology.

\section{Discussion}

Few studies have been conducted on the levels of empathy among mental health nurses [12,31]. Based on our results, participants' empathy scores were relatively high, which is consistent with other nursing research findings [13] suggesting that psychiatric nurses exhibit the highest empathy scores [31]. With regard to gender, there is agreement in the literature that there are significant differences between men and women [12-14]. This is in line with our findings, which also revealed gender-based differences. Furthermore, empathy is directly related to the age of the professionals, the years worked as an unspecialized nurse, and the years worked as a mental health nurse, these results being in line with the international literature $[13,31,43]$.

Burnout was found to increase with age and with the number of years worked as a nurse, especially as a mental health nurse. Although the scientific literature describes empathy as a protective factor against burnout $[43,44]$, in our study we found that higher empathy scores indicate higher levels of burnout. A similar relation between empathy and burnout is reported by Bogiatzaki et al. [13] and Sturzu et al. [12], who attribute it to the intensity of the work involved in emotionally charged settings, such as mental health, compared to other healthcare settings. In these settings, the closeness of the nurse-patient relation and the management of difficult, challenging patient behaviors [45] result in mental health nurses having higher levels of burnout than in other specialties despite exhibiting high levels of empathy [12]. In our study, no significant differences in overall burnout were found between men and women; however, burnout dimensions were related to gender, as men showed higher scores than women on the dimensions of emotional exhaustion and depersonalization and lower scores on personal accomplishment. Bogiatzaki et al. [13] reported that gender is not a strong predictor of burnout, but it is true that scores differ between men and women, as shown in other studies [45]. Ferri et al. [15] state that depersonalization is related to distancing oneself from patients and may constitute a de- 
fense/protection mechanism. The results of a systematic review by Lopez-Lopez et al. [46] suggest that men are less well equipped than women to cope with work-related stress. Furthermore, Sturzu et al. [12] argue that violent incidents and the continuous demands of mental health patients can lead to emotional exhaustion. It is likely that men use the depersonalization mechanism to protect themselves from the stress caused by burnout [13] and that many of them experience emotional exhaustion due to the characteristics of patients with mental disorders [46]. The literature indicates that nurses maintain stability in their personal accomplishments while they are active in care work [47]. However, in our study we observed that personal accomplishment has a non-linear relationship with age, years as a nurse, and years in mental health. This is why there is an increase in personal accomplishment in middle-aged nurses, and after 5 years of working in mental health facilities, since according to the study by Alba-Martín [48] psychiatric services increase the motivational factor of the staff who work in them. This fact, together with the protective behaviors that can arise with patients suffering from a mental disorder [49] informs us of the significant changes in this dimension. However, it was also observed that personal accomplishment decreases in older nurses ( 40 years), from 16 years of experience as a nurse and, especially, from 11 years as a mental health specialist. This result is related to increased emotional exhaustion in this population [12]. Sturzu et al. [12] report that the continuous demands of mental health patients, as well as violent incidents, may lead to higher emotional exhaustion in older professionals and thus lower personal accomplishment.

There is little research on the attitudes mental health professionals hold towards patients with mental disorders [50]. In our study, the various dimensions of attitudes towards patients with mental disorders improve with age and work experience both in general care settings, and, especially and more significantly, in mental health settings, which is in line with a review by Sordi-Carrara et al. [50]. This improvement implies that the dimensions of benevolence and community mental health ideology increase and the dimensions of authoritarianism and social restrictiveness decrease. In addition, there are generally no differences between men and women, which is consistent with other studies $[27,50]$. However, women score higher than men in the dimensions of social restrictiveness and authoritarianism, which may be explained by their display of maternalistic attitudes in their relations with patients with mental disorders [49], given that gender plays an important social role according to Reupert et al. [51]. These attitudes render patients unable to make decisions for themselves and unable to take an active part in their own treatment, sometimes placing them in isolation for the sake of their health, with little contact with other individuals. It was also observed that a higher empathy score significantly improves overall attitudes towards mentally ill patients, as reported by Jung et al. [48]. Furthermore, if empathy is assessed by dimensions, higher levels of empathy are associated with higher levels of benevolence and community health and lower levels of authoritarianism and social restrictiveness among nurses. This phenomenon is linked to age, the number of years as a nurse and, specifically, the number of years as a mental health nurse, which is in consonance with Fradelos et al. [27] and Jung et al. [49].

\section{Conclusions}

This study suggests that high levels of empathy are associated with more positive attitudes towards patients with mental disorders, decreasing their associated stigma. In contrast, empathy did not act as a protective factor against burnout in the study sample.

In addition, the high levels of burnout observed suggest that nurses working with mentally ill patients are highly likely to experience burnout despite their high levels of empathy.

\subsection{Implications for Practice}

Developing empathy skills through training programs would help to increase positive attitudes and decrease stigma towards patients with mental disorders, improving the quality of the care they receive. Futhermore, programs to reduce burnout among mental health 
professionals would thus be necessary to mitigate this problem and increase satisfaction in the work environment, especially in nurses who have been caring for these patients for longer.

Future studies should focus on observing how the study variables behave at other levels of the nursing career, such as nursing degree students and specialty residents being trained in mental health services. This would make it possible to design improvement and development programs specifically tailored to participants and to establish professional continuity in the development of empathy and the reduction of burnout.

\subsection{Limitations}

Firstly, the cross-sectional design of the study constitutes a limitation as it does not allow causal relations to be established. Secondly, the non-probability, non-discriminative, exponential snowball sampling method does not ensure the representativeness of the sample. Third, although this study used instruments adapted and validated in Spanish, and widely used to assess empathy and burnout, the JSE, the MBI, and the CAMI display a number of weaknesses relating to the complex definitions of the three variables they measure and their adaptation to cultures other than English-speaking ones [44,52,53]. Another limitation of our study is that the empathy, burnout and attitudes towards the mentally ill levels were based on questionnaire responses, and there is an obvious risk that the respondents may sometimes have answered what they thought was "expected", rather than what they truly believed. Futhermore, the fact that the data were not normally distributed limited the type and complexity of the statistical analysis and hence the information provided by the data. Finally, the reliability of the scales was good, with the exception of the MBI total score. However, when analyzing the reliability by dimensions, we obtained better figures than those found by Yuguero et al. [44], closer to the reliability figures reported by the MBI questionnaire manual [54]. Like Yuguero et al. [44], we obtained low figures in the depersonalization dimension of burnout. Similar scores to the reliability of our studies can be observed in other studies as well, especially in non-English speaking populations $[44,52]$.

Author Contributions: Conceptualization, D.R.-S. and M.R.L.-M.; Data curation, I.L.-D. and M.R.L.-M.; Formal analysis, J.L.P.-F.; Investigation, J.L.P.-F. and J.M.d.1.F.R.; Methodology, J.C.P.-C. and J.L.P.-F.; Supervision, D.R.-S. Validation, O.P.-C.; Writing—original draft, D.R.-S., J.C.P.-C. and M.R.L.-M.; Writingreview \& editing, D.R.-S., J.C.P.-C., O.P.-C., J.L.P.-F., I.L.-D., J.M.d.l.F.R. and M.R.L.-M. All authors have read and agreed to the published version of the manuscript.

Funding: This research received no external funding.

Institutional Review Board Statement: The study was conducted in accordance with the Declaration of Helsinki, and approved by Ethics Committee of Cadiz (1 April 2019).

Informed Consent Statement: Informed consent was obtained from all subjects involved in the study.

Conflicts of Interest: The authors declare no conflict of interest.

\section{References}

1. Corrigan, P.W.; Wassel, A. Understanding and influencing the stigma of mental illness. J. Psychosoc. Nurs. Ment. Health Serv. 2008, 46, 42-48. [CrossRef]

2. Patten, S.B.; Williams, J.V.; Lavorato, D.H.; Bulloch, A.G.; Charbonneau, M.; Gautam, M.; Moss, P.; Abbey, S.; Stuart, H. Perceived stigma among recipients of mental health care in the general canadian population. Can. J. Psychiatry 2016, 61, 480-488. [CrossRef] [PubMed]

3. Tippin, G.K.; Maranzan, K.A. Efficacy of a photovoice-based video as an online mental illness anti-stigma intervention and the role of empathy in audience response: A randomized controlled trial. J. Appl. Soc. Psychol. 2019, 49, 381-394. [CrossRef]

4. Alenezi, A.; McAndrew, S.; Fallon, P. Burning out physical and emotional fatigue: Evaluating the effects of a programme aimed at reducing burnout among mental health nurses. Int. J. Ment. Health Nurs. 2019, 28, 1042-1052. [CrossRef] [PubMed]

5. Mason, P.; Bartal, I.B.-A. How the social brain experiences empathy: Summary of a gathering. Soc. Neurosci. 2010, 5, 252-256. [CrossRef]

6. Rogers, C.R. The necessary and sufficient conditions of therapeutic personality change. J. Consult. Psychol. 1957, 21, 95-103. [CrossRef] [PubMed] 
7. Mennenga, H.A.; Bassett, S.; Pasquariello, L. Empathy development through case study and simulation. Nurse Educ. 2016, 41, 139-142. [CrossRef]

8. Geyer, N.-M.; Coetzee, S.K.; Ellis, S.M.; Uys, L.R. Relationship of nurses' intrapersonal characteristics with work performance and caring behaviors: A cross-sectional study. Nurs. Health Sci. 2018, 20, 370-379. [CrossRef]

9. Kerasidou, A.; Horn, R. Making space for empathy: Supporting doctors in the emotional labour of clinical care. BMC Med. Ethic 2016, 17, 8. [CrossRef] [PubMed]

10. Torres, O.Y.; Aresté, M.E.; Mora, J.R.M.; Soler-Gonzalez, J. Association between sick leave prescribing practices and physician burnout and empathy. PLoS ONE 2015, 10, e0133379. [CrossRef]

11. Kelm, Z.; Womer, J.; Walter, J.K.; Feudtner, C. Interventions to cultivate physician empathy: A systematic review. BMC Med. Educ. 2014, 14, 219. [CrossRef] [PubMed]

12. Sturzu, L.; Lala, A.; Bisch, M.; Guitter, M.; Dobre, D.; Schwan, R. Empathy and burnout-A cross-sectional study among mental healthcare providers in France. J. Med. Life 2019, 12, 21-29. [CrossRef] [PubMed]

13. Bogiatzaki, V.; Frengidou, E.; Savakis, E.; Trigoni, M.; Galanis, P.; Anagnostopoulos, F. Empathy and burnout of healthcare professionals in public hospitals of greece. Int. J. Caring Sci. 2019, 12, 611-626.

14. Gleichgerrcht, E.; Decety, J. Empathy in clinical practice: How individual dispositions, gender, and experience moderate empathic concern, burnout, and emotional distress in physicians. PLoS ONE 2013, 8, e61526. [CrossRef] [PubMed]

15. Ferri, P.; Guerra, E.; Marcheselli, L.; Cunico, L.; Di Lorenzo, R. Empathy and burnout: An analytic cross-sectional study among nurses and nursing students. Acta Biomed. 2015, 86, 104-115.

16. West, C.P.; Dyrbye, L.N.; Shanafelt, T.D. Physician burnout: Contributors, consequences and solutions. J. Intern. Med. 2018, 283, 516-529. [CrossRef] [PubMed]

17. Maslach, C.; Jackson, S.E. The measurement of experienced burnout. J. Organ. Behav. 1981, 2, 99-113. [CrossRef]

18. Ethirioux, B.; Ebirault, F.; Ejaafari, N. Empathy is a protective factor of burnout in physicians: New neuro-phenomenological hypotheses regarding empathy and sympathy in care relationship. Front. Psychol. 2016, 7, 763. [CrossRef]

19. Petrucci, C.; La Cerra, C.; Aloisio, F.; Montanari, P.; Lancia, L. Empathy in health professional students: A comparative cross-sectional study. Nurse Educ. Today 2016, 41, 1-5. [CrossRef]

20. Vaghee, S.; Sepehrikia, M.; Saghebi, S.A.; Vashani, H.B. Comparison of the effect of face-to-face and multimedia education on the anxiety caused by electroconvulsive therapy in patients with mood disorders. Evid. Based Care J. 2017, 7, 25-34.

21. Bourgault, P.; Lavoie, S.; Paul-Savoie, E.; Grégoire, M.; Michaud, C.; Gosselin, E.; Johnston, C.C. Relationship Between Empathy and Well-Being Among Emergency Nurses. J. Emerg. Nurs. 2015, 41, 323-328. [CrossRef]

22. Szpak, J.L.; Kameg, K.M. Simulation decreases nursing student anxiety prior to communication with mentally ill patients. Clin. Simul. Nurs. 2013, 9, e13-e19. [CrossRef]

23. Corrigan, P.W. Mental health stigma as social attribution: Implications for research methods and attitude change. Clin. Psychol. Sci. Pract. 2000, 7, 48-67. [CrossRef]

24. Corrigan, P.W. Testing social cognitive models of mental illness stigma: The prairie state stigma studies. Psychiatr. Rehabil. Ski. 2002, 6, 232-254. [CrossRef]

25. Link, B.G.; Phelan, J.C. Conceptualizing stigma. Annu. Rev. Sociol. 2001, 27, 363-385. [CrossRef]

26. McAllister, S.; Robert, G.; Tsianakas, V.; McCrae, N. Conceptualising nurse-patient therapeutic engagement on acute mental health wards: An integrative review. Int. J. Nurs. Stud. 2019, 93, 106-118. [CrossRef]

27. Fradelos, E.C.; Velentza, O.; Anastopoulou, K.; Vasiliadi, E.; Argyrou, P.; Mitsi, D.; Tsaras, K.; Alikari, V.; Papathanasiou, I.V.; Zyga, S. Assessment of factors that influence nurses' attitudes towards mental illness. OALib 2015, 2, 1-7. [CrossRef]

28. Gerace, A.; Oaster, C.; O'Kane, D.; Hayman, C.L.; Muir-Cochrane, E.C. Empathic processes during nurse-consumer conflict situations in psychiatric inpatient units: A qualitative study. Int. J. Ment. Health Nurs. 2016, 27, 92-105. [CrossRef]

29. Vaghee, S.; Lotfabadi, M.K.; Salarhaji, A.; Vaghei, N.; Hashemi, B.M. Comparing the effects of contact-based education and acceptance and commitment-based training on empathy toward mental illnesses among nursing students. Iran. J. Psychiatry 2018, 13, 119-127. [PubMed]

30. Moreno-Poyato, A.R.; Rodríguez-Nogueira, Ó. The association between empathy and the nurse-patient therapeutic relationship in mental health units: A cross-sectional study. J. Psychiatr. Ment. Health Nurs. 2021, 28, 335-343. [CrossRef]

31. Soheili, M.; Ghaedi, F.; Ashouri, E.; Sahragerd, M. Nurses' empathy in different wards: A cross-sectional study. Iran. J. Nurs. Midwifery Res. 2020, 25, 117-121. [CrossRef] [PubMed]

32. Payne, A.; Koen, L.; Niehaus, D.J.; Smit, I.-M. Burnout and job satisfaction of nursing staff in a South African acute mental health setting. S. Afr. J. Psychiatry 2020, 26, 1454. [CrossRef]

33. Von Elm, E.; Altman, D.G.; Egger, M.; Pocock, S.J.; Gøtzsche, P.C.; Vandenbroucke, J.P.; STROBE Initiative. The strengthening the reporting of observational studies in epidemiology (STROBE)statement: Guidelines for reporting observational studies. J. Clin. Epidemiol. 2008, 61, 344-349. [CrossRef]

34. Polit, D.; Hunger, B. Investigación Científica en Ciencias de la Salud; McGraw-Hill: Ciudad de México, México, 2000.

35. Lorenzo Ortega, R.; Sonego, M.; Pulido, J.; González Crespo, A.; Jiménez-Mejías, E.; Sordo, L. Métodos indirectos para la estimación de poblaciones ocultas. Rev. Esp. Salud Pública 2017, 91, 1-9.

36. Contreras, J.L.M.; Huizing, E.; Vera, A.M.P.; Cócera, J.A.L.; Cuidados, G.R.Y. Opinión de las enfermeras de salud mental de españa sobre el enfoque de recuperación. Rev. Esp. Enferm. Salud Ment. 2017, 1, 20-27. [CrossRef] 
37. Blanco, J.M.; Caballero, F.; García, F.J.; Lorenzo, F.; Monge, D. Validation of the jefferson scale of physician empathy in spanish medical students who participated in an early clerkship immersion programme. BMC Med. Educ. 2018, 18, 209. [CrossRef] [PubMed]

38. Seisdedos, N. Manual MBI. Inventario "Burnout" de Maslach; TEA: Madrid, Spain, 1997.

39. Maslach, C.; Jackson, S.E.; Leiter, M.P. Maslach Burnout Inventory Manual; Consulting Psychologists Press: Palo Alto, CA, USA, 1996; Volume 4.

40. Ochoa, S.; Martínez-Zambrano, F.; Vila-Badia, R.; Arenas, O.; Casas-Anguera, E.; García-Morales, E.; Villellas, R.; Martín, J.R.; Pérez-Franco, M.B.; Valduciel, T.; et al. Spanish validation of the social stigma scale: Community attitudes towards mental illness. J. Psychiatr. Ment. Health Nurs. 2016, 9, 150-157. [CrossRef]

41. Holm, S. A simple sequentially rejective multiple test procedure. Scand. J. Stat. 1979, 2, 65-70.

42. De Vellis, R.F. Scale development. In Theory and Applications, 2nd ed.; Sage Publications: Thousand Oaks, CA, USA, 2003; Volume 3.

43. Yuguero, O.; Marsal, J.; Esquerda, M.; Galvan, L.; Soler-González, J. Cross-sectional study of the association between empathy and burnout and drug prescribing quality in primary care. Prim. Health Care Res. Dev. 2019, 20, e145. [CrossRef] [PubMed]

44. Yuguero, O.; Forne, C.; Esquerda, M.; Pifarre, J.; Abadías, M.J.; Viñas-Salas, J. Empathy and burnout of emergency professionals of a health region. A cross-sectional study. Am. J. Med. 2017, 96, e8030. [CrossRef]

45. Lamothe, M.; Boujut, E.; Zenasni, F.; Sultan, S. To be or not to be empathic: The combined role of empathic concern and perspective taking in understanding burnout in general practice. BMC Fam. Pract. 2014, 15, 15. [CrossRef] [PubMed]

46. Lopez-Lopez, I.M.; Gomez-Urquiza, J.L.; Canadas, G.R.; De la Fuente, E.I.; Albendin-Garcia, L.; Canadas-De, L.F.G. Prevalence of burnout in mental health nurses and related factors: A systematic review and metaanalysis. Int. J. Ment. Health Nurs. 2019, 28, 1032-1041. [CrossRef]

47. Lopes, A.R.; Nihei, O.K. Burnout among nursing students: Predictors and association with empathy and self-efficacy. Rev. Bras. Enferm. 2020, 73, e20180280. [CrossRef] [PubMed]

48. Martín, R.A. Burnout en enfermería: Prevalencia y factores relacionados en el medio hospitalario. Rev. Cient. Soc. Esp. Enferm. Neurol. 2015, 41, 9-14.

49. Ha, J.H.; Jung, W.; Choi, E.; Yu, J.; Park, D.-H.; Ryu, S.-H. Attitudes toward the mentally ill among community health-related personnel in South Korea. Indian J. Psychiatry 2017, 59, 328-332. [CrossRef]

50. Carrara, B.S.; Ventura, C.A.A.; Bobbili, S.J.; Jacobina, O.M.P.; Khenti, A.; Mendes, I.A.C. Stigma in health professionals towards people with mental illness: An integrative review. Arch. Psychiatry Nurs. 2019, 33, 311-318. [CrossRef]

51. Reupert, A.; Gladstone, B.; Hine, R.H.; Yates, S.; McGaw, V.; Charles, G.; Drost, L.; Foster, K. Stigma in relation to families living with parental mental illness: An integrative review. Int. J. Ment. Health Nurs. 2021, 30, 6-26. [CrossRef] [PubMed]

52. Hemmerdinger, J.M.; Stoddart, S.D.R.; Lilford, R.J. A systematic review of tests of empathy in medicine. BMC Med. Educ. 2007, 7 , 24-28. [CrossRef] [PubMed]

53. Olivares Faúndez, V.; Gil Monte, P. Análisis de las principales fortalezas y debilidades del "Maslach Burnout Inventory" (MBI). In Ciencia \& Trabajo; Ciencia \& Trabajo: Santiago, Chile, 2009; Volume 11, pp. 160-167.

54. Kulakova, O.; Jiménez, B.M.; Garrosa, E.; Hernández, M.O.S.; Aragón, A. Universality of the construct maslach burnout inventory in a Latin American context. Psychol. Rec. 2017, 7, 2679-2690. [CrossRef] 